\begin{tabular}{|c|c|c|c|}
\hline$\Omega$ & $D$ & $\equiv$ & 라 \\
\hline
\end{tabular}

\title{
The second year has been completed
}

\section{News from the Underground}

\section{New chair, new members and many more possibilities}

Among many other things, the last European Respiratory Society (ERS) International Congress in Munich brought changes to the ERS Junior Members Committee (JMC). The 3-year term of JMC representatives has seen Indre Butiene, who initiated the Committee 3 years ago, finish her tenure as chair, with Anders Bjerg, respiratory epidemiologist from Gothenburg, Sweden, being elected as her replacement. Indre's departure has also led to the election of a new representative to the ERS Education Council. We congratulate Agnes Boots from the Netherlands on her election to this important position! Also, here in Breathe, the Doing Science series has been taken over by Georgia Hardavella, UK, whose ideas will take this practical educational series to new levels in 2015. The Hot Topics section is now coordinated by Neil Saad, UK, one of many Juniors outside the JMC who have volunteered for different JMC activities.

As News from the Underground is one window into the current JMC activities, we would like to express our sincere gratitude to Indre for her inspiring leadership during these years. Today, young researchers are represented in all Assemblies and the majority of important working bodies within ERS compared with only a couple of years ago when there was no formal representation. With support from ERS, this entire framework has been built from scratch by ambitious people, and the rapid involvement of junior members is nothing short of astounding.
Today, the JMC and associated junior members are involved in publishing, guidelines, professional education, HERMES (Harmonising Education in Respiratory Medicine for European Specialists) curricula and examinations, planning and execution of scientific meetings, fellowships, courses, task forces, Congress sessions, and many more. After such a fast expansion, we now need to ensure continued dedication going forward. At the forthcoming ERS International Congress in Amsterdam, many of the current JMC members will be replaced and the new JMC members should get all the support they need. Additionally, the expectations of ERS junior members in general need to be surveyed.

Along with the implications for the general representation of junior members in the ERS, we share the view of our Chair, Anders, in aiming for a wide network of junior members. This will ensure that enthusiastic people with key competencies can become engaged in the undertakings of the JMC and of ERS in general. To accomplish this, JMC representatives are asking their respective Assembly Junior members regarding their clinical and research interests and willingness to contribute, and are creating a list of "Junior Competencies". This list can then be used to identify potential chairs and speakers for ERS events.

Finally, we would like to remind you that elections of new JMC representatives in Amsterdam will take place during the Assembly Meetings. Therefore, we recommend those who are interested to contact their respective JMC representative or Assembly official. We look forward to seeing the next generation of junior members carrying this initiative onward. 


\section{ERS Lung Science Conference}

Anne Olland is a junior inolved in the 2015 ERS Lung Science Conference (LSC), which, this year, will dedicated to lung infection and immunity. A special feature has been posted on the ERSnet juniors' homepage (juniors.ersnet.org) to provide visibility for this meeting, mostly dedicated to young ERS members.

This will be a unique occasion to engage junior members in the scientific discussion and to maximise the circulation of ideas. Moreover, the hope of the organising committee is that the informal and relaxed atmosphere of the LSC will encourage young members to accept the opportunity to chair sessions!

Another notable event will be in the Saturday afternoon session dedicated to career building. Last year's session was mostly dedicated to multimodality careers, sharing experience across industry and academic research. This year, it will be mostly dedicated to fellowship opportunities offered to junior members in academia as well as in industry. ERS is trying to maximise fellowships opportunities and increase the possibilities of support to its junior members. Academic and industry partners involved in the ERS programme for short- and long-term fellowships are invited to describe their expectations and their vision of future collaborations with ERS, and also what they will be able to provide junior members from a more practical point of view.

Another new and interesting undertaking, which will be piloted during the upcoming LSC, is to survey the needs and expectations of junior members. The LSC has a convenient format for piloting such projects, and ERS Conferences and Seminars Director Bruno Crestani and ERS have facilitated this. Of course, the JMC can be contacted directly using the JMC website (juniors.ersnet.org) or the individual members' e-mail addresses.

The final results of the survey will be presented as an ouverture at the next junior session in Estoril by our fellowships representative, Agnes Boots.

Finally, the LSC event in Estoril is a quiet, intimate place bringing together a younger crowd compared with the ERS International Congress. The LSC organising committee and the JMC believe that this is the best place to start discussions about a junior member's professional future in the field of respiratory science and medicine. Together, we can make the best of this gathering to expand junior collaboration all over ERS organisation and meetings.

\section{ERS Guidelines Working Group}

Moving towards the future, an important group is the ERS Guidelines Working Group (GWG), in which there is now a permanent position for at least one junior member, which Daan Caudri has accepted.

One of the roles of the junior member is to discuss the progress of ongoing guidelines task forces together with the other members of the GWG. Furthermore, the GWG advises the Science Council on new task force applications.

Importantly, the GWG recently agreed that all newly awarded clinical practice guidelines task forces should include at least one junior member. The JMC and ERS are convinced that involvement of junior ERS members is an ideal way for juniors to participate in clinical and research activities, from which both ERS and the juniors can benefit considerably. Junior members will have to invest time in guidelines development, but will get out of it the opportunity to work together with the leading experts in that particular field. Furthermore, junior members will gain hands-on experience in guidelines development. For this reason, ERS is also exploring different ways to train junior members in guidelines methodology, such as establishing a fellowship programme.

Good quality education and training is of the utmost importance for junior members. They are constantly represented in the HERMES initiative, which aims to improve international educational standards in respiratory medicine. The role of the JMC representative is to advocate for trainees in all pillars of HERMES activities. These include adult and paediatric pulmonological examination, several projects dedicated to various subspecialties of pulmonology, and accreditation process for Adult European Training Centres. This ongoing process is devoted to young people and seeks to ensure high-quality and unified standards in clinical education across Europe. More information on HERMES and its activities can be found at hermes.ersnet.org.

In conclusion, ERS is unique in its positive, encouraging and promoting attitude towards junior its members and therefore it deserves junior devotion and activity. 